\title{
Ideologi dan Hegemoni dalam Shalawatan (Study ff The Ideology of Althusser and Gramsci's Hegemony)
}

\author{
M. Ahsana Ghazalba \\ Fakultas Ilmu Budaya, Universitas Diponegoro \\ ahsanaghazalba@gmail.com
}

\begin{abstract}
This study aims to describe the ideological meaning and the form of hegemonicism in the prayers of the popular Javanese people of their time. Analytical choice The ideological state apparatus initiated by Althusser is used to uncover the play of ideological meaning in prayer. While discussing the Gramsci hegemony, it is used to discuss the domination of the ideological state apparatus. This research method is descriptive qualitative. The object that is read is the meaning of persuasion, identity, appreciation, and punishment in prayer through the study of the state apparatus and hegemony. The result of this research are offer processes containing idealist that have the ability, identification, appreciation and punishment in shalling moral, ethical, and religious people.
\end{abstract}

Keywords: Ideology; hegemony; shalawatan; meaning; identity.

\section{Intisari}

Penelitian ini bertujuan untuk mendeskripsikan makna ideologis dan bentuk penghegemonian dalam shalawatan masyarakat Jawa yang populer di zamannya. Pendekatan analitis Ideological state aparatus yang digagas oleh Althusser digunakan untuk mengungkap permainan makna ideologis dalam shalawatan. Sedangkan pendekatan hegemoni Gramsci digunakan untuk menyoroti pendominasian dari berjalannya Ideological state aparatus. Metode penelitian ini adalah deskriptif kualitatif. Objek yang diteliti adalah makna persuasif, identity, reward, dan punishment dalam shalawatan melalui kajian Ideological state apparatus dan hegemoni. Hasil dari penelitian ini adalah bahwa shalawatan merupakan gagasan ideologis yang memiliki sifat persuasif, identity, reward, dan punishment dalam membentuk masyarakat Jawa yang bermoral, beretika, dan religius.

Kata kunci: Ideologi; hegemoni; shalawatan; makna; identitas.

\section{Pendahuluan}

Salah satu jenis karya Sastra Jawa Pesisir yang berkembang di lingkungan pondok pesantren adalah lahirnya apa yang disebut sebagai sastra pesantren. Demikian yang dinyatakan Abdullah (2012: 1) dalam papernya, aspek esoteris dalam syi'ir erang-erang sekar panjang (suatu edukasi etis dalam sastra pesantren). Melalui pernyataan tersebut, Abdullah tengah mempersoalkan istilah sastra pesantren yang dirujuk dari karya sastra kitab 
(sastra keagamaan), karena sastra pesantren yang berupa syi'ir menyangkut ajaran yang bersifat dogmatis-ritual maupun ajaran yang bersifat rasional-spiritual untuk memperbarui sikap, prilaku dan akhlaq masyarakat Jawa.

Bentuk syi'ir dalam masyarakat Jawa sekarang lebih populer dengan istilah shalawatan. Tradisi membaca shalawatan sering terdengar dan dilakukan oleh masyarakat Jawa Tengah-an maupun Jawa Timur-an. Tradisi membaca shalawatan sekarang menjadi populer di kalangan masyarakat muslim pada umumnya. Misalnya shalawatan ketika menunggu waktu adzan dan iqamat, dengan lafal bacaan shalawatan, baik yang berbahasa Arab atau yang berbahasa Jawa. Lafal shalawatan dalam bahasa Jawa dikenal dengan singiran, yang berisi makna bahasa Jawa dari shalawat Nabi atau syairsyair tentang keagungan Nabi. Adapun pembacaan shalawatan antara adzan dan iqamat dikenal dengan sebutan puji-pujian.

Singiran oleh masyarakat Jawa dalam perkembangannya lebih dikenal dengan sebutan shalawatan. Tetapi, shalawatan di sini dimaksudkan adalah singiran maupun puji-pujian waktu menunggu iqamat. "Singir" diduga berasal dari bahasa Arab syi'ir. Syi'ir berarti syair atau puisi. Menurut Karsono dalam Rahmawati (244: 2015), singir adalah sebuah bentuk seni sastra Jawa yang berbentuk puisi tradisional. Bentuknya hampir mirip dengan syair dalam ranah kesusastraan Melayu. Singir diduga berasal dari syair, bentuk seni sastra Melayu yang masuk ke dalam tradisi sastra Jawa, sebagai akibat persentuhan sastra Jawa dengan sastra Melayu. Singir merupakan sastra tradisional, yang dalam bentuk awalnya ditulis dengan aksara pegon. Rahmawati mengutip pendapat Darnawi (244: 2015) menyatakan bahwa singir adalah salah sebuah hasil kesusastraan jenis puisi beberapa pondok pesantren. Bentuknya sama dengan syair dalam khazanah sastra lama yaitu terdiri atas empat baris. Tiap baitnya bersajak aaaa, dan bersuku kata tetap. Selain itu, umumnya tiap baris berisi dua belas suku kata. Tema dari singir biasanya cerita-cerita yang diambil dari sejarah Islam ataupun dari Al-Qur'an, atau tentang kehidupan ajaranajaran agama Islam.

Dalam hal ini, masyarakat Jawa pesantrenan mempunyai inovasi tersendiri untuk memahamkan ajaran-ajaran agama Islam dalam lingkungannya terhadap norma dan nilai dalam shalawat. Singir bukan hal baru lagi di kalangan pesantren sebab singir sering digunakan sebagai bahan pembelajaran ilmu-ilmu tauhid, fiqih, tarikh, akhlaq, dan ilmu lain yang berhubungan dengan Islam. Pembacaannya biasanya dilakukan dengan 
cara dinyanyikan atau sering disebut dengan singiran. Meskipun naskah ini cukup popular di kalangan santri dengan populasi yang cukup banyak, namun singir masih sangat jarang disinggung dan diperhatikan sebagai bagian dari khazanah kesusastraan Jawa secara umum. Penelitian atas singir juga terbilang masih minim.

Keterangan mengenai singir, Muzakka (2002: 33) menyimpulkan adanya tiga faktor utama yang menjadi penyebab kurang diperhatikannya singir dalam khazanah sastra Jawa, yaitu faktor bahasa, aksara, dan estetika. Bahasa sastra pesisir dan pesantren jauh dari standar bahasa Jawa sebagai baku sebagaimana yang telah berkembang di Surakarta dan Yogyakarta. Aksara yang digunakan sebagian besar berupa aksara pegon (Arab-Jawa), bukan aksara Jawa pada umumnya yang digunakan sebagian besar karya sastra Jawa. Selain itu, nilai estetika (kesastraannya) juga dipandang cukup rendah karena ditulis oleh orang awam (bukan pujangga keraton) yang kurang mengetahui kaidah penulisan sastra Jawa.

Shalawatan ataupun singiran dalam perkembangannya telah memunculkan banyak variasi dalam bentuk dan fungsinya Shalawatan yang pada awalnya merupakan doa rahmat dan salam bagi Nabi, kini berkembang menjadi syair-syair yang berkaitan dengan makna bentuk persuasif, identity, reward, dan punishment dalam ajaran-ajaran agama islam. Oleh sebab itu, shalawatan seperti bentuk persuasif, identity, reward, dan punishment, sekarang ini merupakan sastra populer yang dikenal masyarakat pada umumnya dan khususnya masyarakat Jawa Tengah-an dan Jawa Timur-an, untuk membentuk konsepkonsep dalam menjalankan perintah agama islam. Konsep-konsep seperti itu dapat disebut penanaman ideologi untuk melakukan penghegemonian.

Ideologi secara sederhana dapat dipahami sebagai pengetahuan tentang gagasan yang berkaitan dengan sistem pemikiran, sistem kepercayaan, dan sistem tindakan. Dalam sistem pemikiran, ideologi sering dijadikan alat legitimasi terhadap kebenaran. Dalam sistem kepercayaan ideologi dijadikan landasan keyakinan. Ideologi merupakan upaya untuk menetapkan makna dan pandangan dunia yang mendukung penguasa; peta-peta makna (maps of meaning) yang, meskipun tampak seperti kebenaran universal, sebenarnya merupakan pemahaman - pemahaman yang secara historis bersifat spesifik, yang berusaha menyelubungi dan untuk melanggengkan kekuasaan kelompok kelompok sosial (Barker, 2005: 515 via Ardini, 2016: 31) 
Ideologi menyangkut pandangan hidup merupakan konsep yang dimiliki seseorang atau golongan di masyarakat yang bermaksud menanggapi segala masalah di dunia. Perkembangan zaman dan keadaan sosial berpengaruh terhadap perilaku kehidupan manusia. Pandangan hidup manusia dapat berubah misalnya akibat perkembangan waktu, tuntunan seseorang ataupun masyarakat didalam menghadapi hidupnya itu menuju tujuan akhir.Kluckhon (dalam Muhardi, 1984:19-20 via Putri et al., 507: 2013) menjelaskan bahwa pandangan hidup manusia ideal dengan orientasi budaya. Manusia ideal adalah manusia yang memandang hidup ini buruk, tetapi berusaha untuk mewujudkannya supaya hidup ini menjadi baik. Memandang di masa datang menjadi lebih baik. Dengan demikian, berkarya, berbuat, dan bersikap maju tidak henti-hentinya menjadi alasan untuk memperbaiki masa lalu.

Banyak tokoh yang tertarik pada pembicaraan tentang ideologi, salah satunya adalah Althusser. Althusser mengartikan ideologi sebagai ketidaksadaran yang begitu mendalam (profoundly unconciuous). Ideologi baginya tidak hanya terdapat dalam hubungan dalam suprastruktur dengan substruktur atau antara negara dan rakyat atau hubungan antara buruh dan majikan. Ideologi terdapat pada hubungan yang lain bahkan dalam hubungan sehari-hari orang per orang. Bagi Althusser, ideologi tidak lagi dipandang sebagai kesadaran palsu tetapi merupakan bentuk-bentuk ketidaksadaran yang dalam tertanam pada individu. Oleh karena ideologi adalah salah satu bentuk ketidaksadaran, maka prakteknya dalam diri manusia tidak disadari. Ideologi masuk lewat berbagai sumber terkait dengan struktur masyarakat: keluarga, agama, pendidikan, media massa, dan lain-lain. Menurut Althusser, setiap orang punya yang peranan dalam menyebarkan ideologi dan menjadikan masyarakat ideologis. Ideologi - ideologi ini terbina dari banyak hal seperti mitos, agama, hubungan orang tua-anak, serta hubungan guru dan murid (Takwin, 2003: 85-86).

Hubungannya dengan sebuah teks sastra (via Strorey, 2010: 36-37), menurut Althusser wacana ideologis adalah sebuah sistem yang tertutup. Wacana ideologis sesungguhnya hanya bisa menyelesaikan problem-problem itu sejauh yang mampu ia jawab. Supaya tetap aman di dalam batas-batas yang ditentukannya sendiri, wacana ideologis yang harus tetap diam terhadap pertanyaan - pertanyaan yang mengancamnya untuk keluar dari batas-batas ini. Formulasi ini mengantarkan Althusser pada konsep 'problematika'. Konsep problematika ini singkatnya berpendapat bahwa pada sebuah teks terdapat hal-hal yang tidak ada (apa yang tak terucap) sama banyak dengan apa 
yang ada (apa yang dikatakan), sehingga tugas praktik kritis adalah mendekonstruksi teks (membacanya secara simptomatis) untuk menguak mekanisme problematikanya dan dengan begitu membangun hubungannya dengan kondisi historis eksistensi.

Hegemoni berkaitan dengan cara penyebaran sebuah ideologi. Konsep hegemoni dipopulerkan oleh ahli filsafat politik terkemuka Italia, Antonio Gramsci. Hegemoni menurut Gramsci (dalam Sugiono, 2006: 31via Widyaswari, 2: 2016) adalah menguasai dengan kepemimpinan moral intelektual secara konsensual. Suatu kelompok sosial harus dapat melaksanakan kepemimpinan sebelum memenangkan kekuasaan pemerintahan. Dan menjadi dominan apabila kekuasaan tersebut dijalankan, bahkan jika sudah memegang dominasi tersebut maka harus diteruskan kepemimpinannya.

Hegemoni sebagai alat legitimasi dan dominasi tanpa paksaan tersebut dapat berbentuk hegemoni intelektual, hegemoni sosial, maupun hegemoni kultural. Cara kerja hegemoni sangat halus sehingga kelas sosial yang dihegemoni tidak menyadarinya atau bahkan mendukungnya tanpa sikap kritis sama sekali. Hegemoni intelektual dilakukan melalui sistem pendidikan, hegemoni sosial dilakukan melalui organisasi sosial, adapun hegemoni kultural dilakukan melalui bentuk-bentuk kebudayaan dan gaya hidup

Kekuasaan bukanlah dominasi milik suatu kelas tertentu yang menguasai kelas lainnya, tidak melainkan hubungan persetujuan menggunakan kepemimpinan politik, dan ideologis. Ada beberapa pokok pikiran yang penting sehubungan dengan konsep hegemoni, yaitu (1) dalam sebuah hegemoni, kelompok dalam yang mendominasi berhasil mempengaruhi kelompok yang didominasi untuk menerima nilainilai moral, politik, dan budaya dari kelompok dominan, (2) hegemoni diterima sebagai sesuatu yang wajar, sehingga ideologi kelompok dominan dapat menyebar dan dipraktikkan, (3) nilai-nilai dan ideologi hegemoni ini diperjuangkan dan dipertahankan oleh pihak-pihak dominan sedemikian rupa, sehingga pihak yang didominasi tetap diam dan taat terhadap kepemimpinan kelompok dalam penguasa (Bocock 2007: 26-34 via Hatmoko et al., 3: 2013).

\section{Metode Penelitian}

Pengungkapan makna dan pengkajian cara pandang masyarakat merupakan ranah penelitian kualitatif. Orientasi penelitian ini menitikberatkan pada penggunaan bahasa sebagai praktik dan kontekstualitas (Gubrium et.al dalam Somantri, 2005: 59; Stubbs dalam Slemborouck, 1998-2003:1 dalam Achwandi, 2015: 18). Selain itu, penggunaan teknik interpretasi menjadi 
penting (Purbani, 2010:10). Dengan demikian, pendekatan yang dipakai dalam penelitian ini adalah Ideological state aparatuse dan pendekatan hegemoni.

Sebagai langkah awal, digunakan pendekatan Ideological state aparatuse untuk mengetahui struktur konsep dalam setiap teks, yang meliputi bentuk persuasif, identity, reward, dan punishment. Analisis bentuk persuasif digunakan untuk menemukan makna ajakan dalam sebuah teks. Analisis bentuk identity digunakan untuk menemukan gambaran makna dalam ciri-ciri orang beragama. Analisis reward digunakan untuk memberikan gambaran makna dari orang yang mendapatkan pahala apabila menjalankan perintah agama. Analisis punishment dimaksudkan untuk menggambarkan makna hukuman dari orang yang melanggar larangan agama.

Dalam analisis Ideological state aparatusesebagai struktur konsep dalam setiap teks, yang meliputi bentuk persuasif, identity, reward, dan punishment tidak bisa dilepaskan dari proses hegemoni. Oleh karena itu, analisis ini dilanjutkan dengan pendekatan hegemoni untuk melihat keterkaitan proses suatu teks dalam menciptakan konsep. Selanjutnya, akan dilihat dari sisi interpelasi dan resistensi dari sebuah teks.

Pengumpulan bahan (data) yang digunakan adalah dengan studi pustaka. Bahan yang diambil sebagai objek penelitian berupa teks shalawatan yang diambil dari buku Syi'ir PujiPujian Sepanjang Zaman dan teks lain yang berkaitan dengan objek material dan objek formal penelitian. Cara kerja yang dilakukan ialah membaca, mencatat, dan mengkaji rujukan-rujukan yang berhubungan dengan objek penelitian.

\section{Hasil dan Pembahasan}

Bagian ini membahas bagaimana mengungkap Ideological state aparatuse dan hegemoni dalam shalawatan yang memunculkan makna persuasif, identity, reward, dan punishment. Hal tersebut untuk mempermudah dalam melihat proses hegemoni melalui Ideological state aparatuse.

Setelah membaca shalawatan dengan kacamata teori ideologi Althusser serta hegemoni dan dominasi Gramscy, maka terdapat beberapa ideologi yang terkandung dalam shalawatan ini yang dibagi menjadi empat hal, yaitu ideologi mengenai persuasif, identity, reward, dan punishment. Keempat ideologi tersebut digunakan hanya untuk menganalisis shalawatan tentang bab shalat. Peneliti tidak memilih bab yang lain seperti zakat, puasa, haji, dan pelajaran ngaji dikarenakan tuntutan mengenai shalat lebih sering disampaikan secara hegemoni lewat pengajian atau lewat ceramah-ceramah. Selain itu, shalat adalah hal yang 
pertama untuk menjalin keharmonisan antara manusia dengan Tuhan. Hal tersebut sangat kentara sekali penanaman stigma-stigma untuk melakukan shalat pada masyarakat, namun disampaikan dengan cara yang halus dalam kemasan shalawatan. Hal itu, dapat disebut ideological state apparatus yang berfungsi sebagai penanaman ideologi yang secara sadar maupun tidak sadar telah menghegemoni terhadap suatu keyakinan dalam masyarakat.

Dalam tulisan ini, dibatasi hanya pada bahasan ideologi mengenai persuasif, identity, reward, dan punishment dalam shalat. Berikut adalah bahasan lebih lanjut atas hal-hal tersebut :

\section{Ideologi secara bentuk makna persuasif}

Ideologi secara bentuk persuasif yang dimaksud ajakan yang bertujuan untuk mengubah atau memengaruhi kepercayaan, sikap, dan perilaku seseorang sehingga bertindak sesuai apa yang diharapkan. Oleh karena itu, ideologi secara persuasif mengajak masyarakat agar menjalankan perintah shalat yang kaitannya dengan penelitian ini. Berikut adalah kutipan-kutipan shalawatan berjudul Kereta Jawa yang mengidentifikasikan hal ini.

Kutipan penanaman ideologi secara bentuk persuasif

Ayo kabèh para manungsa//Mumpung urip ning alam donya//Mbok ya padha-padha èlinga//Limang wektu ndang lakonana/ Èlingana yèn wayah panggilan//Yèn wis budhal (o)ra kena wakilan//Disalini nganggo kain putih//Yèn wis budhal ora bisa mulih/)

Dari kutipan di atas kita dapat melihat adanya ajakan atau secara persuasif untuk menjalankan shalat. Teks di atas menunjukkan makna bahwa manusia yang hidup di dunia untuk selalu ingat lima waktu dalam shalat yakni subuh, luhur, ashar, maghrib, dan isya. Selanjutnya, ingatlah kalau adzan berkumandang berarti sudah saatnya berkewajiban melakukan shalat. Karena shalat tidak dapat diwakili oleh siapa pun maka shalatlah sebelum meninggal dunia. Apabila dicermati cara shalawatan berbentuk persuasif dengan teks shalawatan seperti di atas sebenarnya penuh stigma untuk melakukan shalat.

Kutipan di atas perlu dijelaskan lebih mendalam lagi pada kutipan kalimat Èlingana yèn wayah panggilan. Kata panggilan disitu masih bersifat ambigu karena makna panggilan mempunyai maksud arti banyak. Tinggal dilihat dari kalimat sebelum dan setelahnya. Dilihat dari kalimat setelahnya lebih berkaitan daripada kalimat sebelumnya yakni Yèn wis budhal (o)ra kena wakilan berarti maksud dari kata panggilan itu sendiri adalah azan. Adzan berarti mengajak shalat yang apabila dikaitkan dengan kalimat Yèn wis budhal (o)ra kena wakilan berarti shalat itu tidak boleh diwakilkan. Sedangkan kalimat Disalini nganggo kain putih//Yèn wis budhal ora bisa mulih/ adalah maksud dari penegasan kalimat sebelumnya yang berarti 
shalat itu tidak boleh diwakilkan. Karena siapa orangnya yang tidak ingat atas panggilan akan diperingati bahwasannya Disalini nganggo kain putih berarti kain kafan. Kain kafan adalah makna tanda bagi orang muslim yang telah mati Yèn wis budhal ora bisa mulih berari siapa orangnya yang telah mati tidak bisa kembali ke dunia lagi kecuali ilmu yang bermanfaat.

Berbeda dengan kutipan penanaman ideologi secara bentuk persuasif yang berjudul Puji-Pujian Setelah Adzan ini

He sedulur sa uwise ono azdan//ojo podo katungkul omong-omongan//enggal enggal podo wudu terus dandan//mlebu mesjid lakonono kesunatan//solat sunat ojo nganti ketinggalan//nunggu imam sinambi puji-pujian//imam teko dikomati terus sembayang//bar sembayang ojo giri bubar during wiridan/. Kutipan tersebut secara fisik maksud dan maknanya sudah jelas, tidak simbolik. Lirik-liriknya mengandung maksud secara persuasif yang diwakili dengan kalimat He sedulur yang berarti mangajak yakni dengan maksud apabila adzan sudah berkumadang bergegaslah berangkat dan lakukankanlah shalat sunah. Kutipan tersebut sudah jelas berbentuk persuasif untuk menanamkan ideologi agar orangorang tidak menunda-nunda shalat.

\section{Ideologi secara bentuk makna identity}

Ideologi secara bentuk identity merupakan ciri ciri atau tanda-tanda yang merefleksi cerminan pada diri seorang individu yang menjadi ciri khasnya. Identitas sering dihubungkan dengan seseorang sejak lahir, seperti agama, suku, ras, kasta maupun kebangsaan. Di sini, seseorang sering mengaitkan-ngaitkan dengan perlakuan orang lain untuk mendapatkan pengakuan oleh orang pada umumnya, khususnya oleh golongangolongan tertentu. Berikut adalah kutipan-kutipan shalawatan Eman-Eman yang mengidentifikasikan hal ini.

Kutipan penanaman Ideologi secara bentuk identity

Eman-eman temen wong sugih durung sembahyang/l Nabi Sulaiman sugih wis ngelakoni sembahyang/ Eman-eman temen wong mlarat durung sembahyang// Nabi Ayyub mlarat wis ngelakoni sembahyang/ Eman-eman temen wong bagus durung sembahyang// Nabi Yusuf bagus wis ngelakoni sembahyang/ Eman-eman temen wong ayu durung sembahyang// Siti Fatimah ayu wis ngelakoni sembahyang/ Eman-eman temen wong gagah durung sembahyang// Nabi Ibrahim gagah wis ngelakoni sembahyang/

Dari kutipan di atas kita dapat melihat adanya identitas dalam memperlihatkan ciriciri seseorang untuk menjalankan shalat. Teks di atas menunjukkan makna bahwa orang 
kaya, miskin, ganteng, cantik, dan gagah berkewajiban menjalankan shalat, seorang Nabi dan kekasih Allah yang luar biasa dari semua itu tetap menjalankan shalat. Maksud dari teks di atas juga bermaksud orang yang melakukan shalat akan tetap mendapatkan kenikmatan Tuhan yang berbentuk apa pun. Oleh karena itu, penanaman idelogi secara bentuk identitas akan membangun stigma yang lekat untuk membedakan antara orang muslim yang baik dengan orang muslim yang buruk, diukur dari seberapa kita melakukan shalat.

Ada kutipan yang jelas-jelas merupakan bentuk identity, berbeda dengan kutipan di atas yang masih bisa dikatakan bentuk persuasif. Kutipan sebagai berikut yang berjudul Rukun Islam

Rukune islam iku limang perkoro// (1) Ingkang dingin ngucapaken sahadat loro// (2) Kaping pindo manjing wektu kudu solat// (3) Kaping telu lamon sugih aweh zakat// (4) Kaping papat puoso wulan romadhon// (5) Kaping limo munggah haji lamon kuwoso.

Maksud dari kutipan di atas yang merupakan identity dari orang islam yang taat beribadah (shalat) adalah Kaping pindo manjing wektu kudu solat// yang berarti orang islam yang mengetahui waktu shalat wajib hukumnya untuk melaksanakan shalat dan dapat juga berarti siapa orang islam yang tidak taat atau tidak melakukan shalat adalah bukan orang islam. Di sini penghegemonian dalam menanamkan ideologi yang berbentuk identity bersifat kasar atau keras. Hal tersebut dapat dikatakan Repressive State Apparatus umtuk menjaga keyakinan bagi orang muslim.

\section{Ideologi secara bentuk makna reward}

Ideologi secara bentuk reward merupakan penghargaan atau hadiah dan balas jasa yang diberikan oleh Tuhan bila dalam agama. Reward berarti semua bentuk penggajian atau ganjaran kepada seseorang yang rajin atau disiplin menjalankan ketentuan-ketentuan yang telah diberikan. Bentuk reward bisa langsung diberikan, semisal orang yang menjalankan shalat akan dijanjikan kaya dan dapat pula berbentuk tidak langsung, semisal oarang yang menjalankan shalat akan dijanjikan kaya di akhirat kelak. Contoh tersebut hubungannya dalam konteks keagamaan. Reward bertujuan agar seseorang menjadi senang, giat, semangat, dan lebih rajin dalam menjalankan ketentuan-ketentuan yang telah diberikan. Oleh karena itu, shalawatan yang memberikan iming-iming atau reward akan mempengaruhi sudut pandang seseorang apabila dilakukan secara terus-menerus. Berikut adalah kutipankutipan shalawatan berjudul Shalat Jamaah yang mengidentifikasikan hal ini. 
Kutipan penanaman Ideologi secara bentuk reward

Sing sopo wonge ora gelem jamangah solat// mengko ora ulih pitulikur drajat/He poro konco podo sregep jamaah solat//(mengko bakal ulih pitulikur drajat

Dari kutipan di atas jelas memperlihatkan adanya reward atau hadiah pada kalimat pitulikur drajat. Dari kesadaran atau kesadaran palsu kita sudah mendominasi bahwa makna teks di atas adalah orang yang melakukan shalat jamaah akan diganjar atau diberikan imingiming dengan hadiah sebesar 27 drajat. Maksud drajat di sini berarti siapa orangnya yang melakukan shalah berjamaah mendapatkan pahala 27 kali shalat (dilipat gandakan) dibandingkan dengan shalat sendirian yang hanya mendapatkan pahala 1 kali shalat saja dan juga belum tentu mendapatkan hadiah dari Tuhan. Oleh karena itu, penanaman idelogi secara bentuk reward jelas membangun stigma untuk selalu berusaha melakukan shalat jamaah karena masyarakat pada umumnya senang atau tergiur dengan hadiah-hadiah dengan bentuk apa pun.

\section{Ideologi secara bentuk makna punishment}

Maksud dari Ideologi secara bentuk punishment disini yaitu penanaman pikiran-pikiran tertentu yang berhubungan dengan sebuah cara untuk mengarahkan sebuah tingkah laku agar sesuai dengan tingkah laku yang berlaku secara umum. Dalam hal ini, hukuman diberikan ketika sebuah tingkah laku yang tidak diharapkan ditampilkan oleh orang yang bersangkutan atau orang yang bersangkutan tidak memberikan respon - respon atau tidak menampilkan sebuah tingkah laku yang diharapkan. Hukuman berperan besar untuk merubah mindset untuk membentuk konsep pembenaran sesungguhnya. Hukuman yang menghalangi terjadinya pengulangan tingkah laku yang tidak diharapkan. Apabila persoalan punishment dihubungkan dengan ketentuan ajaran-ajaran agama terutama agama islam akan membuat seseorang berpikir dua kali untuk tidak melakukannya. Apalagi dalam permasalahan mengenai shalat pasti membuat seseorang terikat untuk selalu melakukan shalat. Oleh karena itu, penanaman ideologi secara bentuk punishment akan membuat seorang berubah drastis dalam kehidupan kesehariannya.

Berikut adalah kutipan shalawatan berjurdul Ati-Ati Urip Ning Alam Dunyo untuk menjelaskan hal di atas:

Kutipan: Sopo wonge wani ninggalake solat// Titenono yen siro lagi sekarat// Lara banget nganti ora biso sambat Ditekani pirang- pirang malaikat Sa' wuse mati di kubur ditinggal 
lungo// Ditekani malaikat ingkang loro//Malaikat teko ngowo alat sikso//Mulo ngati-ati urip ning alam ndunyo/.

Kutipan di atas merupakan bentuk ideologi secara bentuk punishment, yaitu pembentukan ideologi terhadap masyarakat sehingga masyarakat ketakutan terhadap larangan meninggalkan shalat. Selain untuk pembentukan masyarakat yang taat, penanaman ideologi tersebut berkenaan juga dengan eksistensi sebagai sebuah konsep besar untuk membangun kekuasaan lewat shalawatan seperti salah satunya kutipan di atas. Makna dari kutipan di atas bahwa seseorang yang meninggalkan shalat dengan sengaja akan dihukum dengan siksaan yang tidak dapat dibayangkan manusia karena sangat sakitnya siksa itu. Hal seperti ini tentu menanamkan ideologi untuk tidak melanggar ajaran agama dalam hal shalat.

Kutipan di atas akan dipertagas lagi untuk memperkuat sudut pandang ideologi yang berbentuk punishment yakni dengan kutipan yang berjudul Tauhid sebagai berikut Rasane wong ning neroko// Klabang geni Ulo geni// Rantai geni Godho geni// Cawisane wong kang dosa// Gumampang dawuh pengeran// Ojo gumampang// Tinggal sembahyang// Ono tangis Kelayu-layu// Tangise wong wedi mati// Digedongono dikuncenono// Wong mati mongso wurung. Kutipan tersebut merupakan kelanjutan dari pembahsan ideologi yang berbentuk punishment dengan judul Ati-Ati Urip Ning Alam Dunyo. Maksud dari judul Tauhid dan AtiAti Urip Ning Alam Dunyo adalah sama yakni membahas hukuman bagi orang yang meninggalkan shalat. Namun, maksud kutipan dari judul Tauhid merupakan jelas seacara fisik tidak mengandung makna konotatif karena dari kutipan di atas lebih menekankan makna denotatifnya yang bermaksiudkan orang yang meninggalkan shalat akan takut mati berbeda dengan orang yang selalu ingat untuk melaksanakan shalat. Karena orang yang meninggalkan shalat akan terbayang-bayang neraka dengan seluruh isinya seperti halnya diperlihatkan klabang,ular, rantai, gangguan yang diciptakan dari api. Hal tersebut merupakan penanaman ideologi yang berbentuk punishment.

Selanjutnya, seperti yang telah disinggung dalam pembahasan di atas, selain penanaman ideologi melalui shalawatan terhadap masyarakat, juga terdapat pembentukan kepastian pemikiran bahwa apabila menjalankan perintah Tuhan akan mendapatkan hadiah dan apabila melanggar perintah Tuhan akan mendapatkan hukuman. Dalam hal ini, bisa dikatakan sebuah proses penghegemonian untuk melaraskan sudut pandang dalam menjalani hidup sehari-hari dan atau mempelajari untuk ajaran-ajaran agama yang lebih mendalam. 


\section{Simpulan}

Berdasarkan pembahasan di atas, maka pertanyaan-pertanyaan yang diajukan pada bagian pembuka, dapat disimpulkan sebagai berikut, shalawatan disukai banyak orang karena liriknya penuh nilai-nilai agama dan selain itu juga dalam melantunkan shalawatan dapat mengajak masyarakat mengikuti. Keberhasilan para tokoh untuk menciptakan shalawatan mewujudkan masyarakat yang berbudi luhur. Dan sebagai sastra populer, shalawatan juga mengusung ideologi tertentu. Ideologi yang begitu kentara terasa yakni untuk menjadi masyarakat yang mempunyai sudut pandang bahwa ajaran-ajaran agama yang paling benar adalah ajaran islam saja. Oleh karenanya, peneliti tertarik untuk menganalisa shalawatan untuk membongkar kepastian-kepastian yang sudah tertanam dalam pikiran masyarakat.

\section{DAFTAR PUSTAKA}

Abdullah, Muhammad. 2012. Aspek Esoteris dalam Syi'ir Erang-Earang Sekar Panjang (Suatu Edukasi Etis dalam Sastra Pesantren). Semarang: UNDIP.

Achwandi, Ribut. 2015. Hiperialitas dalam Novel Blankis Karya Arswendo Atmowiloto [Tesis]. Semarang: UNDIP.

Althusser, Louis. 1984. Tentang Ideologi: Strukturalisme Marxis, Psikoanalisis, Cultural Studies. Terjamahan Olsy Vinoli Arnof. Avant-Propos Bagus Takwin. Yogyakarta: Jalasutra.

Althusser, Louis. 2015. Ideologi dan Aparatus Ideologi Negara (Catatan-catatan Investigasi): IndoPROGRESS.

Althusser, Louis. 1971. Lenin and Philosophy and Other Essays (terj. B. Brewster). London: New Left Books; New York: Monthly Review Press.

Ardini, Ni Wayan. 2016. Industrialisasi Musik Pop Bali: Ideologi, Kepentingan, dan Praktiknya. Disertasi. Denpasar: UNUD.

Bocock, Robert. 2007. Pengantar Komprehensif untuk Memahami Hegemoni. Yogyakarta: Jalasutra.

Hatmoko MD, Sumartini, Waluyo. 2013. Hegemoni Moral Nyai Karta Reja Terhadap Spirintil Dalam Novel Jantera Bianglala Karya Ahmad Tohari: Kajian Hegemoni Gramsci. Semarang: UNNES.

Muzakka, Mohammad, dkk. 2002. Kedudukan dan Fungsi Singir bagi Masyarakat Jawa. Semarang: UNDIP.

Nadzirin, 2011. Syi'ir Puji-Pujian Sepanjang Zaman. Kediri.

Putri ME, Abdurahman, Zulfadhli. 2013. Ideologi Tokoh Utama (Wanita) dan Tokoh Tambahan dalam Novel Hanum Karya Mustofa W.H. Padang: UNP

Rahmawati, Salfia. 2015. Ajaran Islam dalam Naskah-Naskah Singir Koleksi Fsui Sebagai Bentuk Persinggungan Budaya Islam-Jawa: Kajian Intertekstualitas. Jakarta: Uinjkt. 
Sugiono, Muhadi. 2006. Kritik Antonio Gramsci Terhadap Pembangunan Dunia ketiga. Yogyakarta: Pustaka Pelajar.

Storey, John. 2010. Cultural Studies dan Kajian Budaya Pop. Yogyakarta: Jalasutra. 